\title{
Studies on Antidiuretic Hormone
}

\section{The Effect of Intravenous Administration of Nicotine Bitartrate and} Hypertonic Saline Solution on ADH Level in Human Plasma

\section{Shinji SAWANO}

The 2nd Department of Internal Medicine, Hokkaido University School of Medicine, Sapporo, Japan

(Director : Professor Keimei Mashimo, M.D.)

The present paper deals with a modified sensitive means for the measurement of plasma $\mathrm{ADH}$ and the experimental results of the application in human subjects.

Weinstein's extraction method for ADH was modified and likewise Share's bioassay method for $\mathrm{ADH}$ was also modified. By using these methods, it was possible to detect $2.5 \mu \mathrm{U}$, where the measurement hitherto has been about $20 \mu \mathrm{U}$.

Studies were made on normal human subjects who were administered intravenously with nicotine bitartrate and hypertonic saline solution to compare the difference in mode of stimulation of the agents on the supraoptic nuclei and also to compare the resulting $\mathrm{ADH}$ release from the neurohypophysis.

It was demonstrated in these studies that the plasma $\mathrm{ADH}$ levels were between 0.7 to $7.2 \mu \mathrm{U}$ per c.c. after nicotine injections and 1.2 to $12.1 \mu \mathrm{U}$ per c.c. after hypertonic saline infusions. At the beginning of the negative free water clearance, the plasma $\mathrm{ADH}$ levels were higher after nicotine injections than that after hypertonic saline infusions, and then gradually decreased. After hypertonic saline infusions, however, the plasma $\mathrm{ADH}$ levels gradually increased and reached a state of equilibrium after approximately 30 minutes.

These results suggest that nicotine directly stimulates the supraoptic nuclei for a short period, and as a result, a large amount of $\mathrm{ADH}$ is released from the neurohypophysis into the blood. On the other hand, hypertonic saline stimulates the osmoreceptor to set up nerve impulses, which reflexly stimulates the supraoptic nuclei and in turn the neurophypophysis.

(pp. 665 676) 